Article

\title{
Using Pro-Environmental Information to Modify Conservation Behavior: Paper Recycling and Reuse
}

\author{
Bruno Wichmann *, Martin Luckert, Katrina Bissonnette, Alyssa Cumberland, Claire Doll, \\ Tanishka Gupta and Yuan Shi \\ Department of Resource Economics \& Environmental Sociology, University of Alberta, 515 General Services \\ Building, Edmonton, AB T6G-2H1, Canada; mluckert@ualberta.ca (M.L.); kbissonn@ualberta.ca (K.B.); \\ cumberla@ualberta.ca (A.C.); cadoll@ualberta.ca (C.D.); tanishka@ualberta.ca (T.G.); yuan.shi@ualberta.ca (Y.S.) \\ * Correspondence: bwichmann@ualberta.ca; Tel.: +1-780-492-0819
}

Academic Editor: Michele Rosano

Received: 18 January 2017; Accepted: 16 February 2017; Published: 20 February 2017

\begin{abstract}
In cases where market policy instruments (e.g., taxes and quotas) are impractical tools to induce conservation behavior, information campaigns may be a valuable option. We use a difference-in-differences strategy to estimate the effectiveness a signage campaign for inducing paper recycling and reuse behavior in computer labs. We find that the implementation of signage with pro-environment appeals increases the probability of conservation behavior (i.e., recycling or reuse) by approximately 13\%, despite the fact that pre-treatment levels of paper recycling and reuse were already at approximately $85 \%$. Our results suggest that pro-environment campaigns can be an effective conservation tool and may be an important policy instrument for policy makers to consider.
\end{abstract}

Keywords: paper recycling; paper reuse; social norms; pro-environment appeals; computer labs

\section{Introduction}

Taxes, subsidies, and quotas are policy instruments sometimes used by policymakers to encourage socially desired behavior. However, there are some economic environments where the implementation of such market-based instruments is challenging. Taxes and quotas are not always politically feasible or practical, and subsidies may add significant burdens to limited government budgets [1]. Moreover, there may be instances, such as with recycling and reuse, where costs of monitoring behavior would be prohibitive. In such cases, policymakers are increasingly interested in mechanisms to influence individual decision-making that are not based on typical manipulations of market prices and quantities.

Policy instruments to address problems in waste management may face particular challenges compared to, for example, conservation programs that discourage consumption. While consumption may be taxed or subsidized at places of sales, it can be impractical to monitor individual behavior toward some types of recycling and waste disposal. For example, in some situations (e.g., schools, universities, and corporate offices) it could be difficult to tax paper disposal that could be recycled, or conversely subsidize paper that is reused or recycled. Accordingly, while energy and water conservation programs may focus on consumption reduction associated with monetary incentives through lower utility bills, recycling and reuse programs may need to rely on pro-environmental appeals.

Such an approach may be based on the "supply of environmentalism" related to psychological and economic concepts [2]. The provision of information may alter behavior by providing "psychic taxes" (with negative information) or "psychic subsidies" (with positive information). The information provided to influence behavior may appeal to social norms, which Scott and Marshall [3] define as a set of rules that determine appropriate and inappropriate values, beliefs, attitudes and behaviors. The authors explain that failure to follow the rules of social norms can result in punishments, including social exclusion. Following the theoretical model of Ferraro and Price [4], we assume that moral values 
are a function of social norms and may affect the conservation decisions of rational economic agents. The provision of information in these contexts may appeal to social norms that change the benefits and costs to individuals, and thereby influence behavior.

There have been numerous information-based initiatives that have attempted to change behaviors that can generate negative social spillovers, such as excessive alcohol consumption, drug use, gambling, and littering [5]. Other studies have shown that information campaigns can be effective in promoting environmental conservation behavior, such as reduced water use [5-8], reduced bottled water consumption [9], increased re-use of hotel towels [10], reduced electric energy consumption [1,11], and increased sustainable transportation behavior [12].

There is also research that suggests that information about recycling can increase recycling behavior [13-15]. The success of such information campaigns could arise because the information provided appeals to, and/or reinforces, accepted social norms and/or attitudes (e.g., [16]). For example, Abbott et al. [17] find evidence that social norms influence recycling in England. Thomas and Sharp [18] observe that a number of studies have found that over time, an increasing number of individuals are recycling regularly to the point where it can be deemed a common behavior. They conclude that recycling is becoming socially normalized in the United Kingdom. Nolan [19] provides a discussion about the normativeness of recycling.

Hornik et al. [20] offer a literature review of the determinants of recycling behavior, highlighting the role of incentives and facilitators. They discuss the limitations of economic incentives in promoting long-term sustainable changes in recycling behavior. They also argue that awareness of the importance of recycling and knowledge about recycling programs is an important facilitator of recycling behavior. Hornik et al. [20] conclude that strategies that increase recycling education and improve social image may induce more consumers to begin recycling.

Another challenge in the literature around information induced behavior arises because information is only one of many types of determinants that can influence behavior, cross-sectionally, and over time. To address this identification issue, it can be useful to have observations before and after a treatment, and controls that do not receive the current information treatments, thereby allowing a difference-in-differences approach. Very few studies have evaluated the impact of information on environmental behavior in such an experimental framework (e.g., [4]) and even fewer with respect to recycling behavior (e.g., [21]). Moreover, to our knowledge, this is the first study to investigate the effectiveness of an information campaign when recycling levels are already high.

The objective of this study is to evaluate the impact of a signage campaign. Our case study concerns the use of paper in university computer labs. We use survey data to obtain difference-in-differences estimates of the effectiveness of the norm-based strategies in promoting paper conservation behavior. By examining university computer labs, we explore the use of pro-environmental appeals in a setting where implementation of typical policy instruments (e.g., taxes, subsidies and quotas) is impractical; a situation common in working environments and offices that regularly consume large amounts of paper (Section 4.1 presents a discussion). Moreover, our sites' recycling and reuse baseline levels were approximately $84 \%$. Our paper explores whether the implementation of signage with pro-environment appeals increases the probability of conservation behavior despite already high levels of recycling and reuse, thereby indicating whether such campaigns can significantly influence conservation behavior over the "last mile".

\section{Methods}

\subsection{The Recycling and Reuse Program}

We designed a program to encourage paper recycling and reuse. The program consisted of improved access to recycling bins and reuse trays. In addition, the program introduced signage regarding paper recycling and reuse. In order to isolate the impacts of the signage, these features were implemented differentially across labs. While we improved access to paper recycling and reuse in both labs, 
we implemented signage with pro-environmental appeals solely in the treatment lab. Therefore, our treatment effect refers to the impact of signage (in addition to improved infrastructure). Details are provided below.

Improved Access: Findings in the literature suggest that there are four key components that contribute to effectively inducing changes in recycling habits: specialized bins for paper recycling, lids on the bins to prevent disposal of unwanted material, bins being in close proximity to directional signs, and the placement of receptacles in all areas of consumption [22,23]. These requirements were satisfied in both labs. Moreover, the number and size of recycling bins and reuse trays reflected the capacity of the computer labs.

Signage: Signage was introduced in only one of the labs (i.e., the treatment lab). Our signage program consisted of three groups of posters mounted on three different walls next to printers. Each group of posters contained three components (see Figure 1). Component (a) was designed to prompt computer lab users to increase their usage of trays facilitating paper reuse. Component (b) was a "print green" poster that contained one of three pro-social appeals regarding consumption and resource use:

"Canadians are among the world's largest consumers of paper products, using 6 million tonnes of paper and paperboard annually"

"24 trees are cut down for every tonne of paper and paperboard produced"

"Approximately 324 litres of water are needed to produce one kilogram of paper"

To improve paper reuse success, we designed a third poster, component (c), which provided instructions on how to reuse paper.

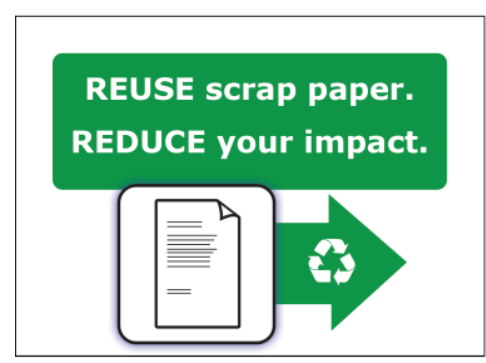

(a)

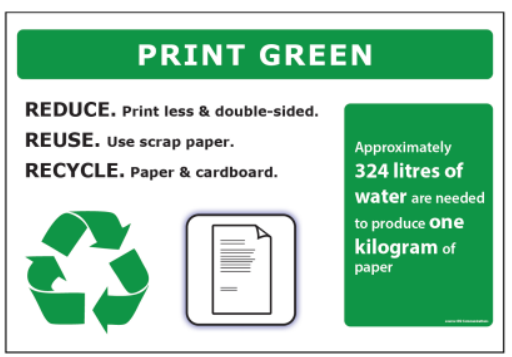

(b)

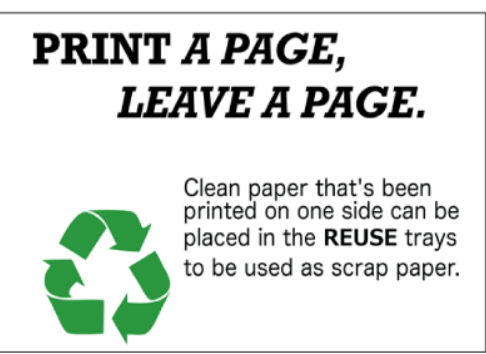

(c)

Figure 1. Signage implemented in the treatment lab; components (a), (b) and (c).

\subsection{Experimental Design}

Our experimental design is motivated by the desire to isolate the effects of the signage treatment from other factors that could influence recycling and/or reuse. There are two categories of factors that could confound this identification: factors that vary cross-sectionally, and factors that vary over time. A difference-in-differences approach can be used to attempt to control for such factors. Therefore, our experimental design includes observations before and after the treatment, and controls during the treatment that do not receive the information treatments.

We surveyed users of two computer labs: the control lab and the treatment lab. These are two large labs centrally located on campus with a distance of approximately $500 \mathrm{~m}$ between one another (i.e., a 6 min walk). Both labs may be used by any student on campus.

A baseline survey was implemented in the fall of 2012 in both labs. Next, the recycling and reuse program described in the previous section was implemented exclusively in the treatment lab in January 2014. In March 2014, we re-surveyed both labs using the same survey instrument that was implemented in the fall of 2012.

Interviewers randomly approached users at both computer labs over the course of a week, to fill out a short survey. Users who had already been surveyed were identified and not surveyed again to 
avoid double counting. Interviewers stated that they were collecting information to help the university office of building and grounds services. A key question was: "What do you most often do with used paper in this computer lab?" Respondents were instructed to choose one of four options: (a) recycle it; (b) use it for scrap paper; (c) throw it in the garbage; (d) other.

Table 1 summarizes our experimental design by showing the number of responses collected in both labs before and after the treatment.

Table 1. Number of observations per treatment cell.

\begin{tabular}{cccc}
\hline Labs & Fall 2012 (Before Treatment) & Winter 2014 (After Treatment) & Total \\
\hline Control & 86 & 146 & 232 \\
Treatment & 46 & 124 & 170 \\
Total & 132 & 270 & 402 \\
\hline
\end{tabular}

\subsection{Program Evaluation}

The experimental design facilitates the use a difference-in-differences regression model to estimate the effect of pro-environment signage on recycling and reuse behavior of computer lab users. This approach allows us to compare our treatment group with a control group, thereby accounting for non-treatment effects over time. We estimate the following probit model:

$$
\operatorname{Prob}(Y=1)=G\left(\beta_{0}+\beta_{1} \text { Post }+\beta_{2} \text { Treatment }+\beta_{3}\left(\text { Post }^{*} \text { Treatment }\right)\right)
$$

where $Y$ is a binary indicator for the selected behavior (i.e., $Y=1$ if paper is recycled, $Y=0$ otherwise), $G$ is the c.d.f. of the standard normal distribution, Post is an indicator for the Winter 2014 (post-treatment) survey, and Treatment is an indicator for the treatment lab.

In our case, the treatment effect is equal to the marginal effect of a change in Post ${ }^{*}$ Treatment from zero to one, holding all other variables fixed. As a result, the estimate of the treatment effect on the probability of observing the selected behavior is:

$$
G\left(\hat{\beta}_{0}+\hat{\beta}_{1} \text { Post }+\hat{\beta}_{2} \text { Treatment }+\hat{\beta}_{3}(\text { Post } * \text { Treatment })\right)-G\left(\hat{\beta}_{0}+\hat{\beta}_{1} \text { Post }+\hat{\beta}_{2} \text { Treatment }\right),
$$

where $\hat{\beta}$ denotes probit parameter estimates, with average levels of Post and Treatment used to evaluate the above expression.

An important identifying assumption of difference-in-differences estimation of treatment effects is that behavior of control and treatment groups are identical, except for the effect of the treatment. We have no reason to believe that users of the control lab have a systematically different approach towards paper recycling or reuse than users of the treatment lab. Nevertheless, we use the Fall 2012 data (pre-treatment) to test if the proportions of selected behaviors (i.e., recycling, reuse and garbage) are statistically different between the two labs. We also note that a given piece of paper can only be associated with one behavior, two of which are conservation-oriented (i.e., recycling and reuse). Therefore, we also present proportions of the combined behaviors of recycling and reuse. Results are presented in Table 2. For all cases, differences between the two labs are not statistically significant. This is empirical evidence that behaviors in both labs are similar before treatment, providing support for the assumption of random treatment assignment. 
Table 2. Tests of equality of proportions between the control and treatment labs prior to treatment (Fall, 2012).

\begin{tabular}{|c|c|c|c|c|}
\hline Labs & $\begin{array}{l}\text { Proportion of } \\
\text { Recycling }\end{array}$ & $\begin{array}{l}\text { Proportion of } \\
\text { Reuse }\end{array}$ & $\begin{array}{c}\text { Proportion of } \\
\text { Recycling or Reuse }\end{array}$ & $\begin{array}{c}\text { Proportion of } \\
\text { Garbage }\end{array}$ \\
\hline Control & $0.430(0.053)$ & $0.430(0.053)$ & $0.861(0.037)$ & $0.128(0.036)$ \\
\hline Treatment & $0.370(0.071)$ & $0.435(0.073)$ & $0.804(0.058)$ & $0.174(0.056)$ \\
\hline \multicolumn{5}{|c|}{$\mathrm{H}_{0}:$ Prop $($ Control $)-$ Prop $($ Treatment $)=0$} \\
\hline$p$-value & 0.499 & 0.960 & 0.401 & 0.473 \\
\hline
\end{tabular}

\section{Results}

Figure 2 shows the distribution of behaviors by lab, before and after the treatment. In the treatment lab, the proportions of respondents recycling and reusing paper increased from Fall 2012 to Winter 2014, while the proportion of respondents throwing paper in the garbage decreased. However, these changes may not have been caused by the information provided by our signs, as social norms as pro-environmental attitudes and behavior may have been increasing over time. Indeed, we see in the control group that recycling also increased over time, while reuse dropped and garbage did not change much.

(a) Control Lab - Fall 2012

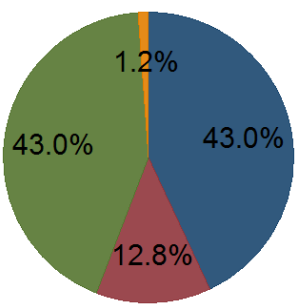

(c) Treatment Lab - Fall 2012

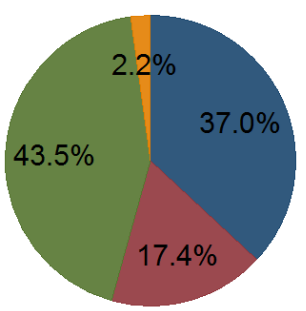

(b) Control Lab - Winter 2014

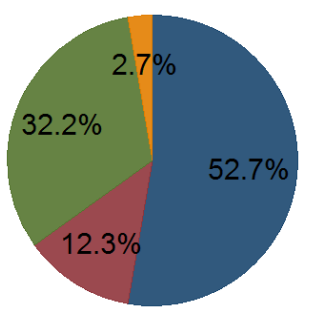

(d) Treatment Lab - Winter 2014

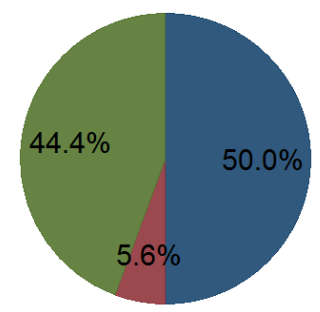

garbage

other

Figure 2. Behavior by lab, before and after treatment.

The difference-in-differences econometric model is able to provide an estimate of the treatment effect of our signage campaign on paper recycling and reuse behavior, while controlling for potential non-treatment changes over time. Table 3 shows the marginal effects of our explanatory variables on the probability of observing the corresponding behavior. Our interest is on the estimates of the treatment effect, i.e., the marginal effect of Post ${ }^{*}$ Treatment on behavior.

We find that our campaign decreased the probability of throwing paper in the garbage by approximately $10 \%$ (fourth column of Table 3). This treatment effect is statistically significant at the $5 \%$ level. However, influences of the signage campaign on the individual behaviors of recycling and reuse, though positive, are not significant. We note, however, that all three behaviors are substitutes for one another, in that a given piece of paper may only end up in one place. Therefore, an alternative 
approach to examining behavior is to aggregate both conservation behaviors (i.e., paper recycling and reuse) in one model (third column of Table 3). In this model, we find that our signage campaign increased the probability of conservation behavior (i.e., recycling or reuse) by approximately $13 \%$, with statistical significance at the $1 \%$ level. As a robustness check, we also estimate a linear probability model and find similar results. Specifically, for the Recycling or Reuse model, the estimated coefficient of Post*Treatment is equal to 0.150 (with $p<0.05$ ); for the Garbage model, we estimate this coefficient to be -0.113 (with $p<0.1$ ).

Table 3. Difference-in-Differences Probit Regressions.

\begin{tabular}{ccccc}
\hline Variable & Recycling & Reuse & Recycling or Reuse & Garbage \\
\hline Post & $0.097(0.067)$ & $-0.111^{*}(0.068)$ & $-0.009(0.040)$ & $-0.004(0.040)$ \\
Treatment & $-0.063(0.092)$ & $0.004(0.089)$ & $-0.045(0.055)$ & $0.036(0.052)$ \\
Post*Treatment & $0.035(0.111)$ & $0.120(0.109)$ & $0.128^{* * *}(0.048)$ & $-0.097^{* *}(0.048)$ \\
\hline
\end{tabular}

Note: The table reports marginal effects. Regressions include a constant. Standard errors are in parenthesis. ${ }^{*} p<0.1$, ${ }^{* *} p<0.05,{ }^{* * *} p<0.01$.

\section{Discussion}

\subsection{Interpretation of Results and Limitations}

In cases where market instruments are impractical, information campaigns have been touted as a means to induce conservation-oriented behavior. Such situations may arise in office environments where it can be impractical to monitor individual behavior toward recycling and waste disposal. Moreover, whereas the use of economic instruments frequently requires significant changes in public policies, which may not be politically appealing, signage campaigns may proceed on an ad hoc basis, undertaken by individual firms without changes in public policy.

Few studies have shown links between such campaigns and changes in behaviors. Moreover, such investigations rarely have data that allow them to control for the host of intervening factors that could also contribute towards changed conservation-oriented behavior. In this study, we conduct a field experiment, with data collected temporally and cross-sectionally. However, there are limitations. The absence of information about characteristics of respondents prevents us from controlling for potential impacts of these differences. Nevertheless, given that both labs are available to all students and are centrally located with small distance from one another, the populations that these labs serve are likely the same. To the extent that we were able to capture a random sample of students in both labs, and that potential temporal changes equally influenced both labs, our difference-in-differences research design allows us to control for changes over time and isolate impacts of the campaign.

Our case study results show that, as a result of an information campaign, throwing paper in the garbage decreased by approximately $10 \%$, and recycling and reusing increased by approximately $13 \%$. Note that these behavioral changes occurred in an environment where almost $85 \%$ of users were already recycling or reusing, so there was not much room left for improvement. Recent research indicates that the changed behavior is lower when conservation is already high. For example, Ferraro and Price [4] show that the effect of social norms on reducing water consumption is $94 \%$ greater for high water users than that for low water users. In cases where recycling and reuse programs have not yet been implemented and paper conservation behavior is low, gains from information campaigns would likely be much higher than our results indicate.

Though such changes in two university computing labs may not seem substantial, implementing such programs on a wide scale could have large impacts on stocks and flows of paper. In 1980, The Economist suggested businesses should strive towards the "paperless office." But since then, global paper consumption has increased by $50 \%$ [24]. The average office worker uses approximately two pounds of paper per day, which corresponds to approximately 10,000 sheets of copy paper every year, or a total of 4 million tons of copy paper a year in the US [25]. Therefore, if information campaigns 
were able to reduce paper waste by approximately $13 \%$, the result could increase paper conservation in American offices by 520,000 tons a year. Moreover, according to the American Forest \& Paper Association, the US supply of printing-writing paper was 20.07 million tons in 2014, while, in the same year, 11.6 million tons of paper were recovered for recycling (a 58\% recovery rate) [26]. If information campaigns were to increase this rate by $13 \%$, printing-writing paper conservation would increase by 2.7 million tons a year.

There are, however, a number of limitations to our study that should be considered in interpreting our results. One potential issue is cross-contamination, which could occur if the treatment (i.e., the placement of signs) influences the control group. As both labs are located on the same campus, we cannot be certain that users interviewed in the control lab were not also users, and influenced by, the signs posted in the treatment lab. Note, however, that a contamination bias would work against the identification of a treatment effect. To the extent that contamination occurs, users of the control lab would increase conservation and the treatment effect found from using our difference-in-differences approach would be less. Accordingly, our estimates may represent lower bounds of the effect of the sign campaign on paper recycling and reuse behavior.

We also note that the findings of this study are drawn from survey data on stated behavior. There is a long standing literature that discusses the advantages and drawbacks of stated preference methods in comparison to revealed preference approaches. For example, Adamowics et al. [27] note that a revealed preference study could use, for instance, data on the weight of recycling bins before and after treatment. For our study, resources available did not allow us to perform a revealed preference investigation. Future research could examine possible differences between stated and revealed preferences estimates of the impact of information campaigns on conservation behavior.

Another potential area for further research arises from recent work suggesting that recycling can lead to increased consumption of waste papers $[28,29]$. To investigate this possibility, data on the whole quantity of paper used before and after the introduction of improved access and pro-environmental signage would be informative.

\subsection{Pro-Environmental Information as Policy Instruments}

Though pro-environmental information can be effective in promoting conservation behavior, a few notes of caution are in order. When economic instruments are used to alter behavior, a key part of the theory and process is the identification and quantification of a negative externality associated with the behavior in question. For example, paper reuse and recycling could be related to positive externalities associated with not harvesting trees, thereby maintaining sequestered carbon and/or providing for wildlife habitat. The values associated with the external costs or benefits are an integral part of setting the level of taxes or subsidies designed to alter behavior. Unlike economic approaches, which typically try to tie specific costs and benefits of changed behavior to specified levels of taxes and subsidies, approaches that provide information have no such basis. For example, in designing our campaign, we did not consider to what extent the conservation behavior that we sought to promote was beneficial.

So long as more of a desired behavior is better, then considering the level of desired behavior may not be a concern. This was the case at the University where our experiment was conducted. However, there may be increased costs and diminishing returns associated with pushing conservation behavior too far. For example, if a paper campaign attempts to divert the last $1 \%$ of paper going to garbage, then the paper going to reuse paper may have little white space remaining, and/or the paper going to recycling may be polluted with high levels of impurities (e.g., tapes, glues, and adhesives). Therefore, such approaches, if taken too far, could be putting paper through costly sorting processes, only to eventually end up in landfills. The basic problem here is that without accounting for benefits and costs (internal and external) we do not know what behavior is optimal. Information campaigns could, therefore, result in behavior that may seem morally correct, but could sacrifice efficiency and use more resources. Another potential weakness of trying to change behavior with information is that 
such approaches can only be effective if they appeal to and reinforce accepted social norms. Existing social norms are not always based on current knowledge and may be slow to evolve. Therefore, addressing arising problems where social norms have not yet been formed may have to be associated with intensive information campaigns if altered behavior is desired.

From a public policy perspective, trying to shape public opinion is not without its problems. When economists seek to design regulatory policies with economic instruments, they generally do so by accepting public values that exist, and attempt to internalize those public values that are not being correctly accounted for. The basis for this libertarian approach is that in a democratic society, values are generally not right or wrong, but the core upon which policy should be based. In contrast, information campaigns may be based on trying to change and mold public values, a concept that is typically more associated with authoritarian societies.

Nevertheless, information campaigns may provide a useful avenue for policy makers, either by themselves, or as complements to other conservation policies. For example, the southeast of Brazil is currently facing its worst drought in nearly a century. As a result, the largest reservoir system serving Brazil's largest city (Sao Paulo) is currently near depletion [30]. In this situation, conservation of water is clearly essential, but policy solutions have not been forthcoming, perhaps because of political procrastination in an election year (note that Brazil had a presidential election in 2014 [31]). With respect to household waste, Waite et al. [32] argue that England is unlikely to meet the EU target to reuse, recycle and compost $50 \%$ of its household waste by 2020 . They identify the unpopularity of collection charges as one of the challenges towards meeting the goal. These are two cases where appeals to social norms with pro-environmental campaigns could potentially help, similar to Ferraro and Price's [4] findings that households that were exposed to social norms consumed approximately $4.8 \%$ less water than the average control group household.

\section{Conclusions}

In this study, we report results of a field experiment designed to evaluate the impact of a signage campaign on the use of paper in university computer labs. Baseline information on paper conservation behavior was collected from users of two similar computer labs at the University of Alberta, Canada. Next, a paper conservation campaign was implemented in one lab through the use of signage with social appeals. A subsequent survey collected post-campaign information on both control and treatment labs. These data allow us to obtain difference-in-differences estimates of the effectiveness of the norm-based strategies in promoting paper conservation behavior. We find that the implementation of signage with pro-environment appeals increases the probability of conservation behavior (i.e., recycling or reuse) by approximately 13\%, despite already high levels of recycling and re-use.

Information campaigns may be an effective means of influencing behavior where market instruments are not viable, or as a complement to other policy alternatives. However, unless we have a clear, and agreed upon, idea of what that behavior should be, such approaches could lead us in directions that are not socially desirable. Fortunately, information campaigns may be implemented on small or large scales, by individual firms or as part of large government programs, so that the approach can be tailored and selectively applied to situations where desired conservation behavior has been identified and agreed upon.

Such was the case with our experiment where signage was added to recycling opportunities. Market instruments were not viable within the context of computing labs, and recycling and reuse were identified by the University as desirable outcomes. Within this context, the results of the information program were impressive in that, despite the fact recycling and re-use were already prevalent, significant increases were achieved for both recycling and re-use. The pervasive and enduring role of paper in offices suggests that these results are not only of statistical significance, but also, at large scales, significant in influencing substantial amounts of recycling and reuse. 
Acknowledgments: Thanks to the University of Alberta Office of Sustainability for providing the pre-treatment data. Also, the University of Alberta Buildings and Grounds Services facilitated the implementation of signage, recycling bins, and paper reuse trays. Special thanks go to Jessie Kwasny who greatly contributed to the operationalization of the project.

Author Contributions: B.W. and M.L. conceived and designed the experiments; K.B., A.C., C.D., T.G., and Y.S. designed signage materials, implemented the experiment (e.g., signage, recycling bins, reuse trays) and collected the post-treatment data; All authors analyzed the data and wrote the paper.

Conflicts of Interest: The authors declare no conflict of interest.

\section{References}

1. Allcott, H. Social norms and energy conservation. J. Public Econ. 2011, 95, 1082-1095. [CrossRef]

2. Glaeser, E.L. The Supply of Environmentalism: Psychological Interventions and Economics. Rev. Environ. Econ. Policy 2014, 8, 228-229. [CrossRef]

3. Scott, J.; Marshall, G. Oxford Dictionary of Sociology; OUP Oxford: Oxford, UK, 2005.

4. Ferraro, P.J.; Price, M.K. Using nonpecuniary strategies to influence behavior: Evidence from a large-scale field experiment. Rev. Econ. Stat. 2013, 95, 64-73. [CrossRef]

5. Schultz, P.W.; Nolan, J.M.; Cialdini, R.B.; Goldstein, N.J.; Griskevicius, V. The constructive, destructive, and reconstructive power of social norms. Psychol. Sci. 2007, 18, 429-434. [CrossRef] [PubMed]

6. Kurz, T.; Donaghue, N.; Walker, I. Utilizing a social-ecological framework to promote water and energy conservation: A field experiment. J. Appl. Soc. Psychol. 2005, 35, 1281-1300. [CrossRef]

7. Ferraro, P.J.; Miranda, J.J.; Price, M.K. The persistence of treatment effects with norm-based policy instruments: Evidence from a randomized environmental policy experiment. Am. Econ. Rev. Pap. Proc. 2011, 101, 318-322. [CrossRef]

8. Richetin, J.; Perugini, M.; Mondini, D.; Hurling, R. Conserving water while washing hands: The immediate and durable impacts of descriptive norms. Environ. Behav. 2016, 48, 343-364. [CrossRef]

9. Van der Linden, S. Exploring beliefs about bottled water and intentions to reduce consumption: The dual-effect of social norm activation and persuasive information. Environ. Behav. 2015, 47, 526-550. [CrossRef]

10. Goldstein, N.J.; Cialdini, R.B.; Griskevicius, V. A room with a viewpoint: Using social norms to motivate environmental conservation in hotels. J. Consum. Res. 2008, 35, 472-482. [CrossRef]

11. Nolan, J.M.; Schultz, P.W.; Cialdini, R.B.; Goldstein, N.J.; Griskevicius, V. Normative social influence is underdetected. Personal. Soc. Psychol. Bull. 2008, 34, 913-923. [CrossRef] [PubMed]

12. Kormos, C.; Gifford, R.; Brown, E. The influence of descriptive norm information on sustainable transportation behavior: A field experiment. Environ. Behav. 2015, 47, 479-501. [CrossRef]

13. Margai, F.L. Analyzing Changes in Waste Reduction Behavior in a Low-Income Urban Community Following a Public Outreach Program. Environ. Behav. 1997, 29, 769-792. [CrossRef]

14. Martinez, M.; Scicchitano, M. Who listens to trash talk? Education and public media effects on recycling behavior. Soc. Sci. Q. 1998, 79, 287-300.

15. Vining, J.; Ebreo, A. Predicting recycling behavior from global and specific environmental attitudes and changes in recycling opportunities. J. Appl. Soc. Psychol. 1992, 22, 1580-1607. [CrossRef]

16. Schwab, N.; Harton, H.C.; Cullum, J.G. The Effects of Emergent Norms and Attitudes on Recycling Behavior. Environ. Behav. 2014, 46, 403-422. [CrossRef]

17. Abbot, A.; Nandeibam, S.; O'Shea, L. Recycling: Social norms and warm-glow revisited. Ecol. Econ. 2013, 90, 10-18. [CrossRef]

18. Thomas, C.; Sharp, V. Understanding the normalisation of recycling behaviour and its implications for other pro-environmental behaviours: A review of social norms and recycling. Resour. Conserv. Recycl. 2013, 79, 11-20. [CrossRef]

19. Nolan, J.M. Using Jackson's return potential model to explore the normativeness of recycling. Environ. Behav. 2015, 47, 835-855. [CrossRef]

20. Hornik, J.; Cherian, J.; Madansky, M.; Narayana, C. Determinants of recycling behavior: A synthesis of research results. J. Socio-Econ. 1995, 24, 105-127. [CrossRef]

21. Iyer, E.; Kashyap, R.K. Consumer recycling: Role of incentives, information, and social class. J. Consum. Behav. 2007, 6, 32-47. [CrossRef] 
22. Austin, J.; Hatfield, D.B.; Grindle, A.C.; Bailey, J.S. Increasing recycling in office environments: The effects of specific, informative cues. J. Appl. Behav. Anal. 1993, 26, 247-253. [CrossRef] [PubMed]

23. Binder, K.J. The Effects of Replacing Dispersed Trash and Recycling Bins with Integrated Waste Receptacles on the Accuracy of Waste Sorting in an Academic Building. Master's Thesis, Western Michigan University, Kalamazoo, MI, USA, 2012.

24. The Economist. Available online: http://www.economist.com/blogs/graphicdetail/2012/04/daily-chart-0 (accessed on 11 January 2017).

25. Mashable. Available online: http://mashable.com/2014/04/22/earth-day-paper-infographic (accessed on 11 January 2017).

26. Paper Recycles. Available online: http://www.paperrecycles.org/statistics/recovery-of-printing-writingpapers (accessed 11 January 2017).

27. Adamowicz, W.; Louviere, J.; Williams, M. Combining Revealed and Stated Preference Methods for Valuing Environmental Amenities. J. Environ. Econ. Manag. 1994, 26, 271-292. [CrossRef]

28. Catlin, J.R.; Wang, Y. Recycling gone bad: When the option to recycle increases resource consumption. J. Consum. Psychol. 2013, 23, 122-127. [CrossRef]

29. Cecere, G.; Mancinelli, S.; Mazzanti, M. Waste prevention and social preferences: The role of intrinsic and extrinsic motivations. Ecol. Econ. 2014, 107, 163-176. [CrossRef]

30. The New York Times. Available online: https://www.nytimes.com/2015/02/17/world/americas/droughtpushes-sao-paulo-brazil-toward-water-crisis.html (accessed on 11 January 2017).

31. Reuters. Available online: http://www.reuters.com/article/2014/10/31/us-brazil-wateridUSKBNOIK1RL20141031 (accessed on 11 January 2017).

32. Waite, S.; Cox, P.; Tudor, T. Strategies for local authorities to achieve the EU $202050 \%$ recycling, reuse and composting target: A case study of England. Resour. Conserv. Recycl. 2015, 105, 18-28. [CrossRef]

(C) 2017 by the authors; licensee MDPI, Basel, Switzerland. This article is an open access article distributed under the terms and conditions of the Creative Commons Attribution (CC BY) license (http:/ / creativecommons.org/licenses/by/4.0/). 